Article

\title{
Predictive Value of Early Post-Treatment Diffusion-Weighted MRI for Recurrence or Tumor Progression of Head and Neck Squamous Cell Carcinoma Treated with Chemo-Radiotherapy
}

\author{
Esteban Brenet $^{1, *}$, Coralie Barbe ${ }^{2}$, Christine Hoeffel ${ }^{3}$, Xavier Dubernard ${ }^{1}$ (D), \\ Jean-Claude Merol ${ }^{1}$, Léa Fath ${ }^{4}$, Stéphanie Servagi-Vernat ${ }^{5}$ and Marc Labrousse ${ }^{1}$ \\ 1 Department of Oto-Rhino-Laryngology, Head and Neck Surgery, Robert Debré University Hospital, \\ 51100 Reims, France; xdubernard@chu-reims.fr (X.D.); jcmerol@chu-reims.fr (J.-C.M.); \\ mlabrousse@chu-reims.fr (M.L.) \\ 2 Clinical Research Unit, Robert Debré University Hospital, 51100 Reims, France; cbarbe@chu-reims.fr \\ 3 Department of Radiology, Robert Debré University Hospital, 51100 Reims, France; \\ choeffel-fornes@chu-reims.fr \\ 4 Department of Oto-Rhino-Laryngology, Head and Neck Surgery, University Hospital of Strasbourg, \\ 67000 Strasbourg, France; lea.fath@chru-strasbourg.fr \\ 5 Department of Radiotherapy, Institut Godinot, 51100 Reims, France; \\ stephanie.servagivernat@reims.unicancer.fr \\ * Correspondence: ebrenet@chu-reims.fr
}

Received: 10 April 2020; Accepted: 10 May 2020; Published: 14 May 2020

check for updates

\begin{abstract}
Aims: To investigate the predictive capacity of early post-treatment diffusion-weighted magnetic resonance imaging (MRI) for recurrence or tumor progression in patients with no tumor residue after chemo-radiotherapy (CRT) for head and neck squamous cell carcinoma, and, to assess the predictive capacity of pre-treatment diffusion-weighted MRI for persistent tumor residue post-CRT. Materials and Method: A single center cohort study was performed in one French hospital. All patients with squamous cell carcinoma receiving CRT (no surgical indication) were included. Two diffusion-weighted MRI were performed: one within 8 days before CRT and one 3 months after completing CRT with determination of median tumor apparent diffusion coefficient (ADC). Main outcome: The primary endpoint was progression-free survival. Results: 59 patients were included prior to CRT and 46 (78.0\%) completed CRT. A post-CRT tumor residue was found in 19/46 (41.3\%) patients. In univariate analysis, initial ADC was significantly lower in patients with residue post CRT $(0.56 \pm 0.11$ versus $0.79 \pm 0.13 ; p<0.001)$. When initial ADC was dichotomized at the median, initial ADC lower than 0.7 was significantly more frequent in patients with residue post CRT $(73.7 \%$ versus $11.1 \%, p<0.0001)$. In multivariate analysis, only initial ADC lower than 0.7 was significantly associated with tumor residue (OR = 22.6; IC [4.9-103.6], $p<0.0001)$. Among 26 patients without tumor residue after CRT and followed up until 12 months, 6 (23.1\%) presented recurrence or progression. Only univariate analysis was performed due to a small number of events. The only factor significantly associated with disease progression or early recurrence was the delta ADC $(p=0.0009)$. When ADC variation was dichotomized at the median, patients with ADC variation greater than 0.7 had time of disease-free survival significantly longer than patients with ADC variation lower than 0.7 (377.5 [286-402] days versus 253 [198-370], $p<0.0001)$. Conclusion and relevance: Diffusion-weighted MRI could be a technique that enables differentiation of patients with high potential for early recurrence for whom intensive post-CRT monitoring is mandatory. Prospective studies with more inclusions would be necessary to validate our results.
\end{abstract}


Keywords: head and neck neoplasm; diffusion-weighted magnetic resonance imaging (MRI); recurrence; chemo-radiotherapy

\section{Introduction}

Head and neck cancer is the fifth most common cancer, representing $5.3 \%$ of all cancers, with 890,000 new cases worldwide in 2017 [1,2].

Prognosis is frequently poor and is closely correlated with tumor status. Most cases are diagnosed at a locally advanced stage [3]. Chemo-radiotherapy (CRT) protocols are standard first line treatment for head and neck squamous cell carcinoma (HNSCC), either as part of an organ preservation strategy or in cases where surgery has initially been ruled out, as is the case for locally advanced tumors [4-14].

Furthermore, these cancers characteristically have a high recurrence rate, approximately $25 \%$ [15]. Diagnosis of local and lymph node recurrence is a vital part of monitoring patients under treatment for HNSCC. Such monitoring should be particularly intensive for patients who are most at risk, but more importantly, for patients who are candidates for curative treatment [16,17]. The purpose of early diagnosis of locoregional recurrence is to offer curative treatment [18]. This is because local recurrence promotes lymph node recurrence which in turn promotes onset of metastasis $[19,20]$. Very early diagnosis of recurrence facilitates curative treatment and improvement in quality of life [19,21,22].

Yet, within the context of follow-up care in these patients, monitoring procedures are at times suggestive of suspected tumor recurrence without diagnostic support from clinical examination or conventional imaging assessment. Treatment-related mucosal changes occasionally complicate identification of this type of recurrence, from both a clinical and a radiological standpoint. In which case, a wait-and-see attitude should be adopted.

Diffusion-weighted imaging (DWI) differentiates tissues on the basis of molecular water mobility on a microscopic scale, which is indirectly determined by tissue cellularity. Apparent diffusion coefficient (ADC) measures the rate of diffusion of water molecules within a tissue. A low value for DWI/ADC indicates that the tissue is well organized, while a high value for ADC indicates that the tissue is not well organized [23].

Numerous reports have shown the usefulness of DWI/ADC in oncology [24-27]. According to the literature, ADC values can discriminate malignant and benign lesions [28-30]. Usually, malignant tumors have lower values in comparison to benign lesions [31-33]. Several studies have suggested that the characteristics of tumors on magnetic resonance imaging (MRI)/DWI, especially ADC values, commonly correlate with histologic characteristics known as poor prognosis in HNSCC as well as in rectal, pelvic, cerebral and breast tumors [29,32,34-36], and thus predict both long-term survival and resistance to CRT [37]. Other studies have suggested that MRI/DWI is a potentially valuable tool for early detection of responders to chemotherapy, thus enabling rapid adjustment to the therapeutic strategy of non-responders during treatment $[38,39]$. Changes in the diffusion coefficient occur sooner than morphological changes visible on conventional imaging, generating a significantly higher rise in $\mathrm{ADC}$ values in responders than in non-responders [26,40].

The importance of MRI/DWI in predicting early recurrence or disease progression soon after completion of CRT has yet to be assessed.

The main aim of the present study was to investigate the predictive capacity of early post-treatment high b-value images derived from DWI, with particular focus on ADC variation between pre-treatment diffusion-weighted MRI and post-treatment diffusion-weighted MRI (delta ADC), for recurrence or tumor progression in patients with no tumor residue 3 months post treatment by CRT for primary HNSCC.

The secondary aim was to assess the predictive capacity of pre-treatment high b-value images derived from DWI in the absence of total response to CRT. 


\section{Materials and Methods}

\subsection{Patients}

A single center cohort study was performed between April 2014 and April 2018. All patients older than 18 years old, beginning CRT for not operable or not resectable HNSCC, or with laryngeal/hypopharyngeal cancer, for which organ preservation was decided in Reims university hospital, and who accepted to participate in the study, were included. Patients with contra-indication to MRI were excluded.

Every patient that agreed to participate in the study provided informed written consent. This study was approved by the Ethics Committee (CPP Est III, Nancy, 5 November 2013) and retrospectively registered in clinicaltrials.gov (NCT02862678; 11 August 2016).

\subsection{Data Collection and Outcomes}

Baseline patients' characteristics (age, sex, tobacco, alcohol consumption) and baseline tumor characteristics (size, location, Tumor/Node/Metastasis classification (TNM) stage) were recorded.

Concerning patients without tumor residue after completing CRT, a 12-month follow-up was performed. Tumors were considered as recurrent if, from 6 months post-treatment onwards, histology specimens prompted by clinical and radiological findings confirmed squamous cell carcinoma. Tumors were considered as progressive if, between 3 and 6 months post-treatment, histology specimens prompted by clinical and radiological findings confirmed squamous cell carcinoma.

\subsection{Diffusion-Weighted MRI}

Two high b-value images derived from DWI scans were performed for each patient: one prior to initiating CRT, a maximum of 8 days before starting the CRT protocol, including determination of tumor ADC (ADC1), and one within 3 months of CRT completion, including determination of tumor ADC (ADC2).

MRI/DWI sequences were all obtained from the same university teaching hospital MRI scanner: the 3 Tesla MRI system (MAGNETOM, Avanto, Siemens ${ }^{\circledR}$ ). Routine protocol was followed, combining T1-weighted, T2-weighted and T1-weighted with gadolinium contrast injection sequences (standard MRI). Diffusion-weighted sequences were then acquired with a voxel size of $1.9 \times 1.9 \times$ $3.0 \mathrm{~mm}$, 3-gradient diffusion weighting, and b1 value $=0 \mathrm{~s} / \mathrm{mm}^{2}$, b2 value $=500 \mathrm{~s} / \mathrm{mm}^{2}$ and b3 value $=1000 \mathrm{~s} / \mathrm{mm}^{2}$ (Figure 1$)$.

The sequences thus obtained were then analyzed using COME VE10F, NUMARIS/4, Siemens ${ }^{\circledR}$ software (Siemens AG, Muenchen, Germany).

The DWI/ADC coefficient was calculated by two different radiologists with experience of more than 5 years in imaging the head and neck. Readers were blinded from each over and from clinical results.

The measurement of DWI/ADC was carried out on the whole of the tumor, including on the areas of necrosis on the surface of the tumor on 3 sections with the largest diameter in axial sections. 3 measurements were performed for each tumor and the ADC mean coefficient was chosen [41,42].

\subsection{Statistical Analysis}

Data were described as mean and standard deviation (SD) for quantitative variables and number and percentage for qualitative variables.

The inter-reader reproducibility for DWI/ADC measurement was studied using intra-class correlation coefficient (ICC). An ICC > 0.7 indicates good reproducibility [43].

Factors associated with recurrence or disease progression, notably delta ADC, were studied using univariate analysis (Log-rank tests). No multivariate analysis could be conducted due to the small sample size of the study. Median delta ADC of all patients without tumor residue after completing CRT was used as a threshold to optimally differentiate patients with and patients without recurrence or disease progression. 


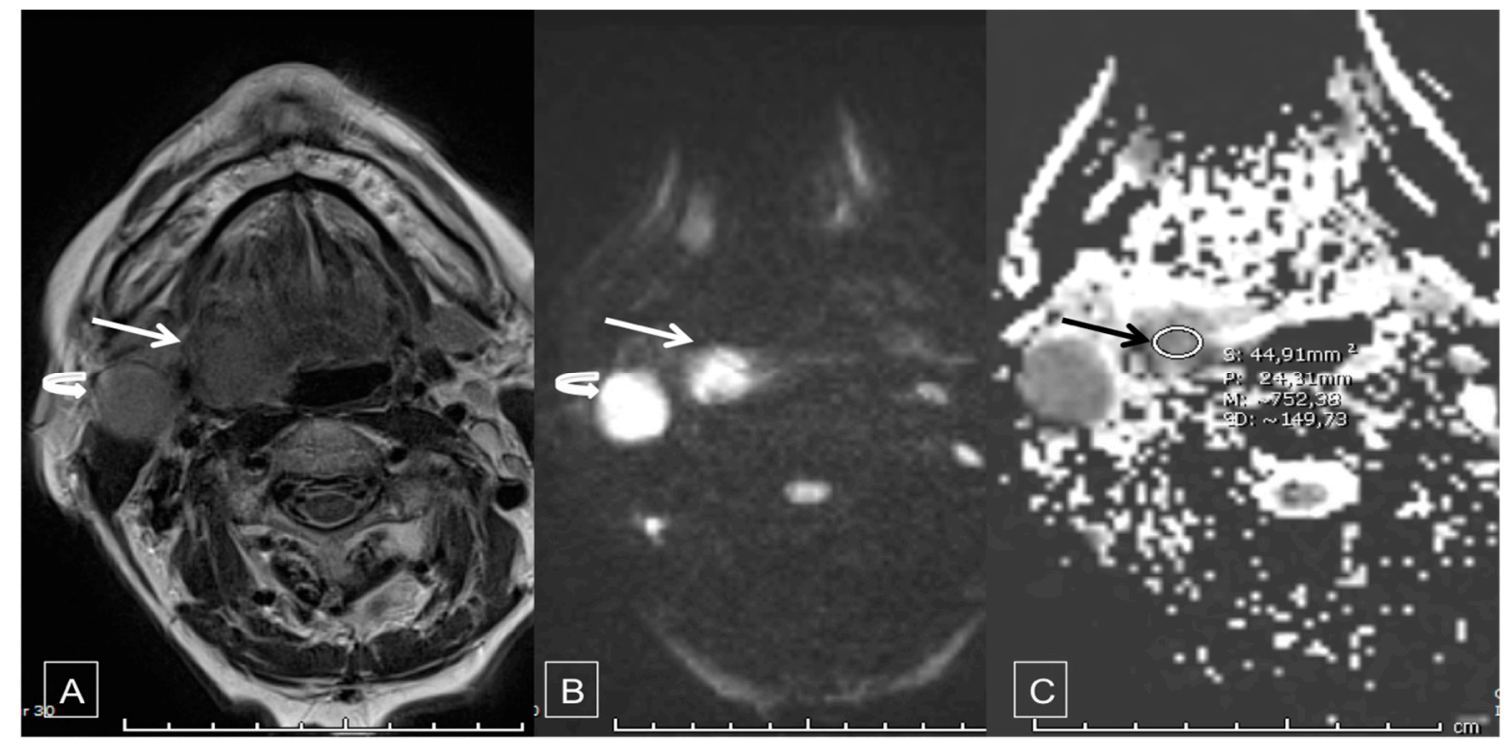

Figure 1. 75-year-old female patient before treatment: (A) Axial T2, (B) high b-value (b = 1000), diffusion-weighted Magnetic Resonnance (MR) images show a $2 \mathrm{~cm}$ large lesion on the right tonsil extending anteriorly to the posterior border of the base of the tongue (arrow), along with a $2 \mathrm{~cm}$ large adenopathy in the II B area (curved arrow). These lesions exhibit markedly high signal intensity in image (B). (C) Apparent diffusion coefficient (ADC) map show restriction of diffusion in both the lymph node and the lesion, with a mean value of the ADC of $0.75 \mathrm{~s} / \mathrm{mm}^{2}$.

Factors associated with presence of tumor residue, notably ADC1 value of the tumor, were studied using univariate analysis (Wilcoxon, Chi-square and Fisher's exact tests, as appropriate) and multivariate analysis (stepwise logistic regression with entry and removal thresholds of 0.20 and variables with a $p<0.20$ by univariate analysis included). Median ADC1 of all patients completing CRT was used as a threshold to optimally differentiate patients with and patients without post-CRT tumor residue.

Sensitivities, specificities, positive predictive values (PPV) and negative predictive values (NPV) with 95\% confidence intervals (CIs) were calculated for each ADC threshold.

A $p$ value $<0.05$ was considered statistically significant. All analyses were performed using SAS version 9.4 (SAS Inc., Cary, NC, USA).

\section{Results}

\subsection{Patients' Characteristics, Treatment and Follow-up}

The flow-chart of the study is shown in Figure 2. Between 4 April 2014 and 22 April 2018, 59 patients with HNSCC were included. The first diffusion-weighted MRI scan was performed within the 8 days prior to treatment initiation for all patients. Thirteen patients (22\%) died during or just after (during the 3 months post-treatment) radiotherapy due to tumor progression, despite treatment. Tumor progression during the treatment was responsible for a deterioration of the general state, requiring the stop of the treatments and leading the patient to need palliative care.

Forty-six (78\%) patients completed CRT and the second diffusion-weighted MRI scan was performed at 3 months after completing CRT for all of them.

Patient clinical characteristics, tumor characteristics and therapeutic management are detailed in Table 1. Mean age was $60.8 \pm 12.1$ years old. Most patients were male $(84.7 \%)$ and had active tobacco consumption (71.2\%). All patients have unique location HNSCC. 

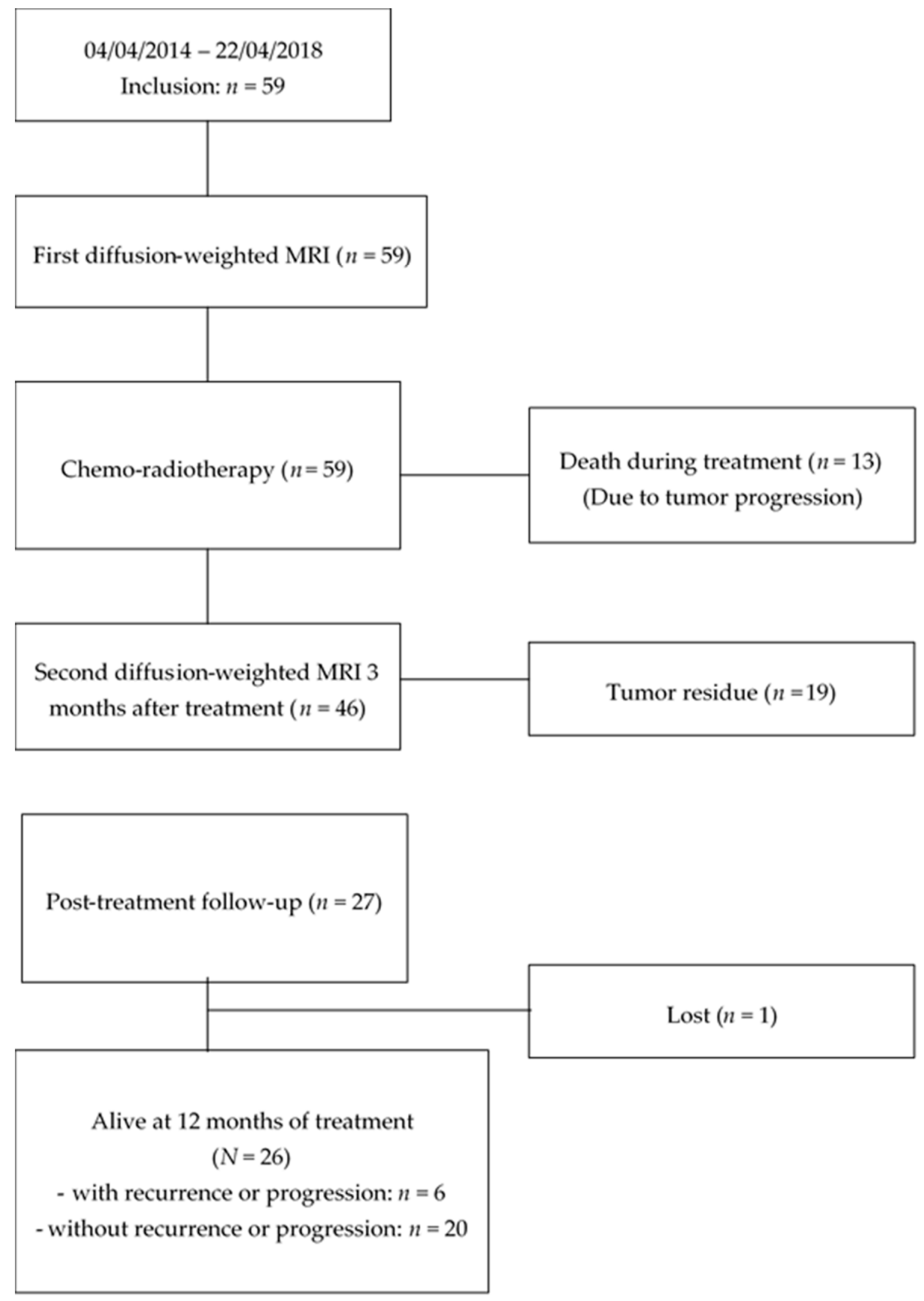

Figure 2. Flow-chart of the study. 
Table 1. Baseline clinical characteristics of patients, characteristics of tumors and treatment modalities decided.

\begin{tabular}{|c|c|}
\hline Characteristics $^{1}$ & Value \\
\hline Patients & \\
\hline Age at inclusion (year) - Mean \pm SD & $60.8 \pm 12.1$ \\
\hline Sexe Ratio $(\mathrm{M} / \mathrm{F})$ & $50 / 9$ \\
\hline \multicolumn{2}{|l|}{ Tobacco use } \\
\hline No & $8(13.6)$ \\
\hline Yes & $51(86.4)$ \\
\hline Active & $42(82.4)$ \\
\hline weaned & $9(17.6)$ \\
\hline Alcohol & $25(42.4)$ \\
\hline Body Mass Index $(\mathrm{kg} / \mathrm{m} 2)-$ Mean $\pm \mathrm{SD}$ & $23.9 \pm 4.9$ \\
\hline \multicolumn{2}{|l|}{ Head and Neck Tumor } \\
\hline Unique location & $59(100)$ \\
\hline Location & \\
\hline Oropharynx & $33(55.9)$ \\
\hline Oral cavity & $8(13.6)$ \\
\hline Larynx & $7(11.9)$ \\
\hline Hypopharynx & $8(13.6)$ \\
\hline Cavum & $1(1.7)$ \\
\hline Sinus & $1(1.7)$ \\
\hline Parotid gland & $1(1.7)$ \\
\hline \multicolumn{2}{|c|}{ HPV status (among oropharynx location) } \\
\hline Positive & $13 / 33(39.4)$ \\
\hline Negative & $20 / 33(60.6)$ \\
\hline \multicolumn{2}{|l|}{ TNM classification } \\
\hline $\mathrm{T} 1$ & $4(6.8)$ \\
\hline $\mathrm{T} 2$ & $5(8.5)$ \\
\hline T3 & $9(15.2)$ \\
\hline $\mathrm{T} 4$ & $41(69.5)$ \\
\hline No & $9(15.2)$ \\
\hline N1 & $8(13.6)$ \\
\hline $\mathrm{N} 2 \mathrm{a}$ & $1(1.7)$ \\
\hline $\mathrm{N} 2 \mathrm{~b}$ & $10(17.0)$ \\
\hline $\mathrm{N} 2 \mathrm{c}$ & $22(37.3)$ \\
\hline N3 & $9(15.2)$ \\
\hline M0 & $57(96.6)$ \\
\hline M1 & $2(3.4)$ \\
\hline \multicolumn{2}{|l|}{ Histology } \\
\hline Squamous cell carcinoma & $59(100)$ \\
\hline \multicolumn{2}{|l|}{ Différentiation } \\
\hline Well & $28(47.5)$ \\
\hline Middle & $24(40.7)$ \\
\hline Poor & $7(11.9)$ \\
\hline \multicolumn{2}{|l|}{ Therapeutic sequence decided } \\
\hline Induction chemotherapy & $10(17.0)$ \\
\hline Radiotherapy & $59(100)$ \\
\hline Exclusive & 19 \\
\hline With Cetuximab & 25 \\
\hline With Cisplatine & 15 \\
\hline
\end{tabular}

\footnotetext{
${ }^{1}$ Data are presented as $n(\%)$ unless otherwise indicated.
} 
Among patients with oropharyngeal cancer, ADC1 primary tumor value was significantly greater in patients with positive HPV status $(\mathrm{HPV}+)$ than in patients with negative HPV status (HPV-) $(0.76 \pm$ 0.17 versus $0.64 \pm 0.13 ; p=0.03)$.

Ten patients $(17 \%)$ had benefits from 3 cures of induction chemotherapy, consisting of a basic regimen of cisplatin $\left(75 \mathrm{mg} / \mathrm{m}^{2}\right)$, docetaxel $\left(75 \mathrm{mg} / \mathrm{m}^{2}\right)$ and 5 -fluorouracil $\left(750 \mathrm{mg} / \mathrm{m}^{2}\right)$, otherwise known as TPF (Taxane, Platine, 5-Fluoro-uracil), per course of treatment.

All patients underwent on-tumor-site radiotherapy or radio-chemotherapy with a prescribed dose of 70 Gy (2 Gy per fraction) in Simultaneous Integrated Boost, with, in case of radio-sensitization, 3 courses of cisplatin $100 \mathrm{mg} / \mathrm{m}^{2}$ or Epithelial Growth Factor Receptor (EGFR)-targeted therapy, such as cetuximab, weekly $\left(400 \mathrm{mg} / \mathrm{m}^{2}\right.$ loading dose 8 days prior to radiotherapy, followed by a course of $250 \mathrm{mg} / \mathrm{m}^{2}$ weekly, concurrent with radiotherapy). Full-dose radiotherapy was administered to the tumor site in 51 patients (86\%) and reduced-dose radiotherapy was administered to 8 patients (14\%) because of toxicity grade 3 or 4 (6 patients $(11 \%)$ ) or deterioration of general condition (2 patients $(3 \%))$. Among the 8 patients who did not have access to full-dose therapy at the tumor site, $8(100 \%)$ died during or just after (during the 3 months post-treatment) radiotherapy due to tumor progression, despite treatment.

The inter-observer reproducibility, as assessed by the ICC, was high, with ICC $=0.92$ [95\% CI: 0.87-0.94] for the first diffusion-weighted MRI (before RCT) and ICC $=0.98$ [95\% CI: 0.97-0.99] for the second diffusion-weighted MRI (after CRT completion).

\subsection{Factors Associated with Tumor Residue}

Among the 46 patients completing CRT, 19 (41.3\%) had tumor residue. Twelve patients (43.5\%) had macroscopic tumor residue on clinical examination. Twenty-five patients (54.3\%) had tumor residue on the second diffusion-weighted MRI. Among the 25 patients with tumor residue on the second diffusion-weighted MRI, squamous cell carcinoma was confirmed histologically based on biopsy results in 19 patients $(76 \%)$.

Univariate and multivariate analysis of factors associated with post-CRT tumor residue are summarized in Table 2. In univariate analysis, only ADC1 primary tumor value was significantly associated with tumor residue $(0.56 \pm 0.11$ in patients with tumor residue versus $0.79 \pm 0.13$ in patients without tumor residue; $p<0.0001$ ) (Figure 3a). When ADC1 was dichotomized at the median, ADC1 lower than 0.7 was significantly more frequent in patients with tumor residue $(73.7 \%$ versus $11.1 \%$, $p<0.0001)$. In multivariate analysis, ADC1 less than 0.7 was the only factor significantly associated with tumor residue $(\mathrm{OR}=22.6$ [4.9-103.6], $p<0.0001)$.

Among the 46 patients completing CRT, 25 patients had oropharyngeal cancer. Among them, $9(36.0 \%)$ had tumor residue. Univariate and multivariate analyses of factors associated with post-CRT tumor residue among the 25 patients with oropharyngeal cancer were performed. In univariate analysis, ADC1 primary tumor value was significantly associated with tumor residue $(0.59 \pm 0.08$ in patients with tumor residue versus $0.81 \pm 0.09$ in patients without tumor residue; $p=0.0009$ ). When ADC1 was dichotomized at the median, ADC1 lower than 0.7 was significantly more frequent in patients with tumor residue (7/8 patients $(87.5 \%)$ versus $2 / 17$ patients $(11.8 \%), p=0.0005)$. HPV status was not significantly associated with tumor residue (2/12 patients with positive HPV status (16.7\%) versus $7 / 13$ patients with negative HPV status $(53.8 \%) ; p=0.10)$. Variables included in multivariate analysis were ADC1 less than 0.7 and HPV status. In multivariate analysis, ADC1 less than 0.7 was the only factor significantly associated with tumor residue (OR $=53.8$ [4.8-600.3], $p=0.001)$. 
Table 2. Univariate and multivariate analysis of factors associated with the presence of a tumor residue after chemo-radiotherapy.

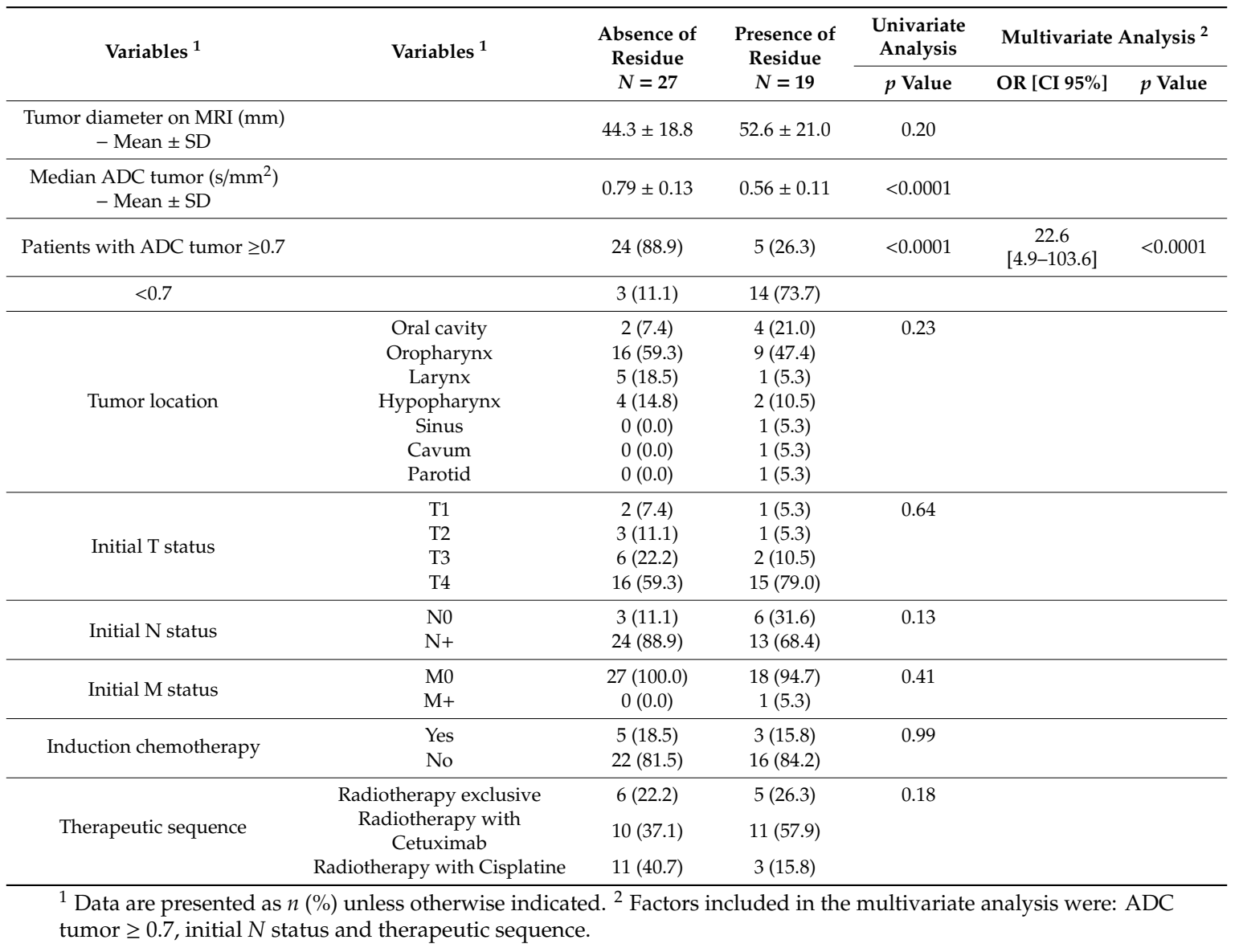

\subsection{Factors Associated with Post-Treatment Disease Progression or Early Recurrence}

A total of 27 patients with no tumor residue remained part of the study follow-up for a 12 months period. Among them, 1 (3\%) patient was lost to follow-up. Early recurrence or disease progression was observed in $6(23 \%)$ of the 26 patients. At the end of study follow-up, $20(74.1 \%)$ patients survived without recurrence.

Univariate analysis of factors associated with post-treatment disease progression or early recurrence is summarized in Table 3.

The only factor significantly associated with disease progression or early recurrence was the delta $\operatorname{ADC}(p=0.0009)$ (Figure 3B).

When ADC variation was dichotomized at the median, patients with ADC variation greater than 0.7 had time of disease-free survival significantly longer than patients with ADC variation lower than 0.7 (377.5 [286-402] days versus 253 [198-370], $p<0.0001$ ) (Figure 4).

Among the 26 patients with no tumor residue and followed up for a 12-month period, 16 had oropharyngeal cancer. Early recurrence or disease progression was observed in 4 (25.0\%) of the 16 patients. The only factor significantly associated with disease progression or early recurrence was the delta $\operatorname{ADC}(p=0.0001)$. When ADC variation was dichotomized at the median, patients with ADC variation greater than 0.7 had time of disease-free survival significantly longer than patients with ADC variation lower than 0.7 (380 [286-402] days versus 253 [198-353], $p=0.02)$. Patients with positive HPV status tended to have longer time of disease-free survival than patients with negative HPV status (348 [253-396] days versus 289 [198-402] days; $p=0.05$ ). 
Table 3. Factors associated with progression or early recurrence after chemo-radiotherapy in univariate analysis.

\begin{tabular}{|c|c|c|c|}
\hline Variables & Variables $^{1}$ & $\begin{array}{l}\text { Time of Disease-Free } \\
\text { Survival (Days) }\end{array}$ & $\begin{array}{c}\text { Univariate Analysis } \\
p \text { Value }\end{array}$ \\
\hline $\begin{array}{l}\text { Tumor diameter at first } \\
\text { MRI }(\mathrm{mm}) \\
\text { Mean } \pm \text { SD }\end{array}$ & & & 0.31 \\
\hline $\begin{array}{c}\text { Delta ADC } \\
(\mathrm{ADC} 2-\mathrm{ADC} 1) \\
\text { Mean } \pm \text { SD }\end{array}$ & & & 0.0009 \\
\hline $\begin{array}{l}\text { Patients with Delta ADC } \\
\text { (ADC2-ADC1) }\end{array}$ & $\begin{array}{l}\geq 0.7 \\
<0.7\end{array}$ & $\begin{array}{c}377.5[286-402] \\
253[198-370]\end{array}$ & $<0.0001$ \\
\hline Induction chemotherapy & $\begin{array}{l}\text { Yes } \\
\text { No }\end{array}$ & $\begin{array}{l}343[253-396] \\
353[198-402]\end{array}$ & 0.82 \\
\hline Therapeutic sequence & $\begin{array}{c}\text { Radiotherapy exclusive } \\
\text { Radiotherapy with Cetuximab } \\
\text { Radiotherapy with Cisplatin }\end{array}$ & $\begin{array}{l}336[243-386] \\
338[198-396] \\
370[225-402]\end{array}$ & 0.35 \\
\hline Tumor location & $\begin{array}{l}\text { Oral cavity } \\
\text { Oropharynx } \\
\text { Larynx } \\
\text { Hypopharynx }\end{array}$ & $\begin{array}{c}342.5[315-370] \\
346[198-402] \\
348[243-391] \\
383[343-394]\end{array}$ & 0.71 \\
\hline Initial $\mathrm{T}$ status & $\begin{array}{l}\mathrm{T} 1 \\
\mathrm{~T} 2 \\
\mathrm{~T} 3 \\
\mathrm{~T} 4\end{array}$ & $\begin{array}{c}319.5[253-386] \\
381[280-389] \\
340.5[243-391] \\
357[198-402]\end{array}$ & 0.69 \\
\hline Initial $\mathrm{N}$ status & $\begin{array}{l}\mathrm{N} 0 \\
\mathrm{~N}+\end{array}$ & $\begin{array}{l}350[198-402] \\
300[243-357] \\
\end{array}$ & 0.28 \\
\hline Initial M status & $\begin{array}{l}\text { M0 } \\
\text { M+ }\end{array}$ & $\begin{array}{c}350.5[198-402] \\
-\end{array}$ & - \\
\hline
\end{tabular}
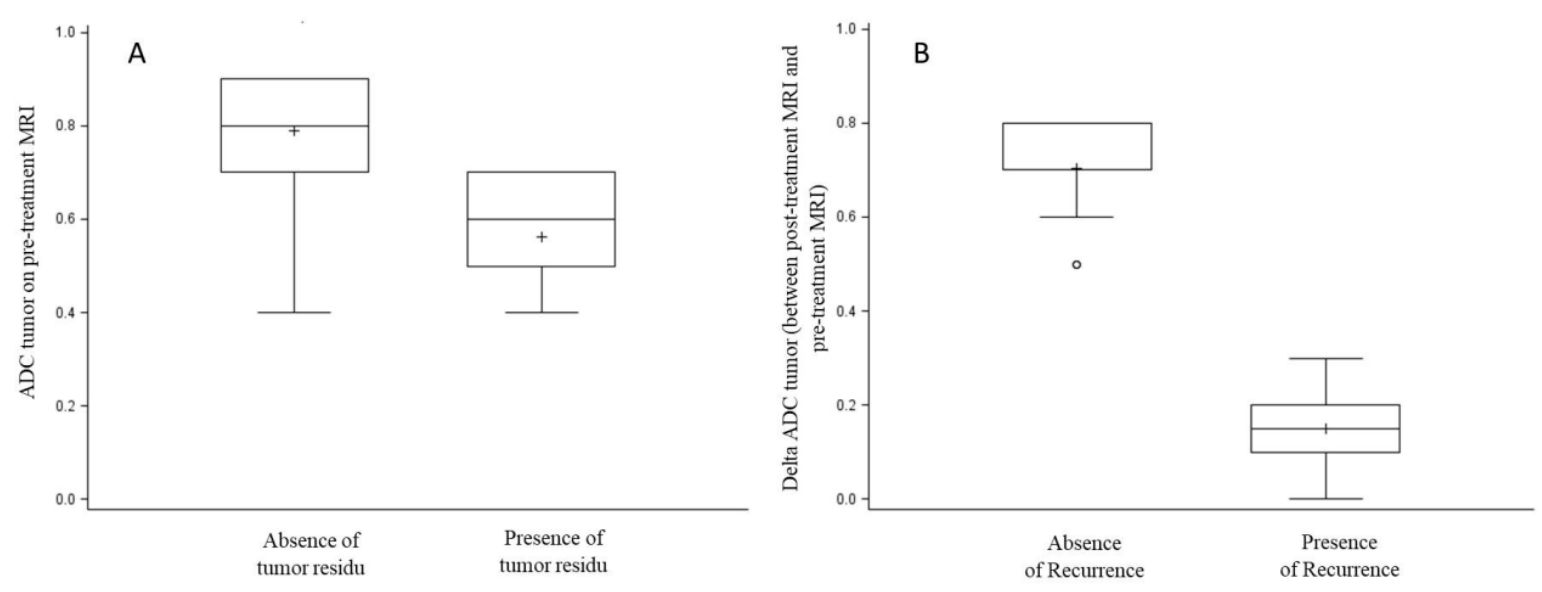

Figure 3. Factors associated with tumor residu (A) and early recurrence (B). (A) Box plot presenting ADC tumor value on pre-treatment MRI according to tumor residu, (B) Box plot presenting delta ADC tumor between post-treatment MRI and pre-treatment MRI according to recurrence. Each box shows median (as line), quartiles and mean (as cross). The whiskers represent values below the first quartile and above the third quartile within the 1.5-fold inter-quartile range respectively, and outliers beyond the whiskers are shown as circles. 


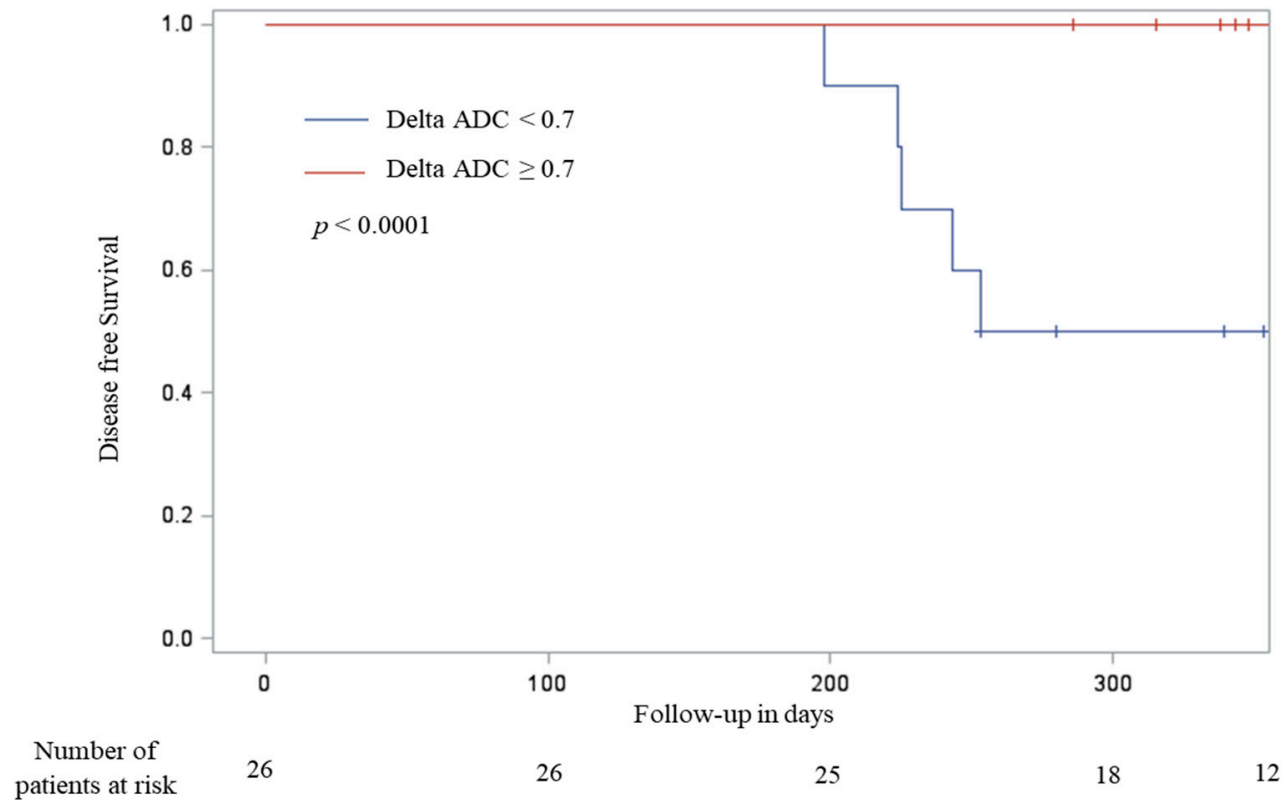

Figure 4. Recurrence-free survival according to tumor delta ADC (greater or lower than 0.7).

\section{Discussion}

The present study thus makes compelling arguments in support of the benefits of diffusion-weighted MRI as a powerful predictive tool for post-CRT early recurrence or tumor residue in HNSCC.

Our study highlights the fact that an increase in ADC (delta ADC) between initial pre-treatment MRI (ADC1) and follow-up MRI at 3 months (ADC2) of less than 0.7 was associated with disease progression or recurrence, and therefore necessitates more intense monitoring.

Furthermore, our study demonstrates that ADC1 values of less than 0.7 also predict post-CRT tumor residue, thus indicating treatment failure, contrary to $\mathrm{ADC} 1$ above this threshold that significantly predicts a positive response. This second point is indeed in accordance with the existing literature [37].

To our knowledge, this is the only prospective study that has assessed diffusion-weighted MRI for this indication and yielded highly significant results with ADC or delta ADC thresholds that clearly differentiate relapse-free survival probability.

Our findings corroborate the conclusions of retrospective trials that have assessed diffusion-weighted MRI in the detection of residual disease or recurrence in head and neck cancers. Some authors [44] have reported diffusion coefficient sensitivity at $94.6 \%$ and specificity at $95.9 \%$ at 6 months post-CRT. However, the study in question involved interpretation of precancerous mucosal lesions, regional lymphatic nodes and low-risk mucosal irradiation. In the same vein, other authors have reported sensitivity at $84 \%$ and specificity at $90 \%$, although there was strong variability in tumor histology and irradiation procedures [45]. Lastly, other authors have produced less impressive results, with sensitivity at $67 \%$ and specificity at $86 \%$ in irradiated laryngeal and hypopharyngeal cancer [46].

Two noteworthy prospective studies were conducted during the post-CRT monitoring period. A prospective trial involving 29 patients assessed the percentage variance of tumor diffusion coefficients pre-treatment and at 3 weeks post-treatment using two-year locoregional control as the primary endpoint. The authors reported sensitivity and specificity at $89 \%$ [47]. The second trial assessed variance of the same diffusion coefficients in the periods before, during and after treatment (at 6 months post-treatment) in patients suffering from head and neck cancers and treated with CRT or radiotherapy alone. Reduction in ADC during or after treatment was 100\% specific for recurrence within 6 months. Post-treatment ADC was more predictive of 12 month regional control than pre-treatment ADC or ADC during treatment, with sensitivity at $80 \%$ and specificity at $100 \%$ [48]. 
On the histologic point, our findings can be interpreted with more necrosis and cell death during therapy. Some authors also showed that ADC reflects the underlying microenvironment of cancers [31]. The positive correlation of ADC and stromal component could suggest that the poor prognostic value of high pretreatment ADC might partly be attributed to the tumor-stroma component, a known predictor of local failure [31].

Our study also demonstrated a correlation between ADC and HPV status with a higher ADC within an HPV+ tumor. On the contrary, some authors showed that ADC mean and median were statistically significantly lower in p16-positive tumors [49]. Others did not find any correlation between ADC and HPV status [32].

It is also of interest to compare these results with those of an alternative imaging technique that is under assessment for the purposes of monitoring: positron emission tomography combined with computed tomography (PET/CT). Several studies have investigated post-treatment monitoring, based on the hypothesis that a significant decrease in mean SUV between pre- and post-therapeutic periods was suggestive of reduced post-treatment glucose metabolism in tumor cells. Certain authors have suggested that PET/CT is more sensitive than $\mathrm{CT}$ alone in detecting post-radiotherapy disease persistence [50]. Others have emphasized that all patients whose post-radiotherapy SUV was less than 3.0 were free from viable residual tumor cells [51]. It is, however, equally important to note that SUV measurement may be affected by variables such as imaging system and its calibration, dosage of the markers used, time elapsed since irradiation and patient serum glucose levels, such that SUV alone is inappropriate for assessing tumor response. Furthermore, radiation-induced changes may also result in increased SUV [52]. The purpose of a currently ongoing French therapeutic trial is to highlight the benefits of intensive monitoring, with emphasis on the inclusion of several PET/CT scans, by comparison with conventional monitoring methods.

Moreover, diffusion-weighted MRI would appear to be more efficient than PET/CT in earlier and more specific detection of persistent diseases. Indeed, several studies have compared these two monitoring procedures [51] along with the advantages of combining the two [53,54], but not from a prospective point of view.

Such early detection of recurrence or disease progression has a direct impact on patient management in terms of both overall survival and comorbidity. Indeed, retrospective data indicates that locoregional control is enhanced by faster salvage treatment [55-57]. Likewise, postoperative complication rates linked to surgical salvage would appear to rise in proportion to time elapsed due to an increase in radiation-induced fibrosis [55,57-59].

One of the limitations of this study was its small sample size with low event rate and absence of external validation. Nevertheless, the effects that were measured had sufficient power to yield functional, practical results that were able to be exploited statistically and corroborated the results of similar prior retrospective studies.

A further limitation arises from the heterogeneity of the head and neck cancer sites. On the basis of the promising results yielded by the present study, it would be of interest to engage in larger-scale research to determine more homogenous populations in terms of cancer sites, given that each site has its own individual prognostic factors.

\section{Conclusions}

The present study makes compelling arguments for the use of pre- and post-chemo-radiotherapy diffusion-weighted MRI in head and neck cancers. This technique brings about differentiation of patients with high potential for recurrence who necessitate intensive post-CRT monitoring. It also facilitates detection of early recurrence or disease progression, thus enabling faster, more efficient implementation of salvage treatment. Finally, diffusion-weighted MRI could be a useful tool to predict failure before CRT. Prospective studies with more inclusions would be necessary to validate our results. 
Author Contributions: Conceptualization, E.B., M.L. and C.H.; methodology, C.B.; software, C.B.; validation, E.B., M.L. and C.H.; formal analysis, E.B.; investigation, E.B. and J.-C.M.; resources, C.B.; data curation, E.B. and C.B. and C.H.; writing-original draft preparation, E.B. and C.B. and S.S.-V.; writing-review and editing, E.B., X.D., J.C.M., S.S.-V. and L.F.; visualization, X.D., J.C.M., S.S.-V. and L.F.; supervision, M.L.; project administration, C.B.; funding acquisition, M.L. and C.B. and C.H. All authors have read and agree to the published version of the manuscript.

Funding: The study was funded by the French Great East local tender 2013 APA13048.

Conflicts of Interest: The authors declare no conflict of interest.

\section{References}

1. Aupérin, A. Epidemiology of head and neck cancers. Curr. Opin. Oncol. 2020, 32, 178-186. [CrossRef] [PubMed]

2. $\quad$ Fitzmaurice, C.; Allen, C.; Barber, R.M.; Barregard, L.; Bhutta, Z.A.; Brenner,H.; Dicker, D.J.; Chimed-Orchir, O.; Dandona, R.; Dandona, L.; et al. Global, regional, and national cancer incidence, mortality, years of life lost, years lived with disability, and disability-adjusted life-years for 32 cancer groups, 1990 to 2015: A systematic analysis for the global burden of disease study. JAMA Oncol. 2017, 3, 524-548. [PubMed]

3. Périé, S.; Meyers, M.; Mazzaschi, O.; Chanel, O.D.C.; Baujat, B.; Guily, J.L.S. Epidemiology and anatomy of head and neck cancers. Bull Cancer 2014, 101, 404-410. [CrossRef] [PubMed]

4. Buiret, G.; Combe, C.; Favrel, V.; Pommier, P.; Martin, L.; Ecochard, R.; Fayette, J.; Tartas, S.; Ramade, A.; Ceruse, P. A Retrospective, Multicenter Study of the Tolerance of Induction Chemotherapy With Docetaxel, Cisplatin, and 5-Fluorouracil Followed by Radiotherapy With Concomitant Cetuximab in 46 Cases of Squamous Cell Carcinoma of the Head and Neck. Int. J. Radiat. Oncol. 2010, 77, 430-437. [CrossRef] [PubMed]

5. Ceruse, P.; Cosmidis, A.; Belot, A.; Rabilloud, M.; Fuchsmann, C.; Poupart, M.; Ramade, A.; Tartas, S.; Favrel, V.; Pommier, P.; et al. A pyriform sinus cancer organ preservation strategy comprising induction chemotherapy with docetaxel, cisplatin, and 5-fluorouracil, followed by potentiated radiotherapy. Anti-Cancer Drugs 2014, 25, 970-975. [CrossRef] [PubMed]

6. Fayette, J.; Bonnin, N.; Ferlay, C.; Lallemant, B.; Ramade, A.; Favrel, V.; Zrounba, P.; Chabaud, S.; Pommier, P.; Poupart, M.; et al. Neoadjuvant TPF in locally advanced head and neck cancer can be followed by radiotherapy combined with cisplatin or cetuximab. Anti-Cancer Drugs 2013, 24, 623-629. [CrossRef] [PubMed]

7. Pointreau, Y.; Atean, I.; Fayette, J.; Calais, G.; Lefebvre, J.-L. Induction chemotherapy in head and neck cancer. Anti-Cancer Drugs 2011, 22, 613-620. [CrossRef] [PubMed]

8. Lefebvre, J.-L.; Chevalier, D.; Luboinski, B.; Kirkpatrick, A.; Collette, L.; Sahmoud, T. Larynx Preservation in Pyriform Sinus Cancer: Preliminary Results of a European Organization for Research and Treatment of Cancer Phase III Trial. J. Natl. Cancer Inst. 1996, 88, 890-899. [CrossRef]

9. Department of Veterans Affairs Laryngeal Cancer Study Group; Wolf, G.T.; Fisher, S.G.; Hong, W.K.; Hillman, R.; Spaulding, M.; Laramore, G.E.; Endicott, J.W.; McClatchey, K.; Henderson, W.G.; et al. Induction chemotherapy plus radiation compared with surgery plus radiation in patients with advanced laryngeal cancer. N. Engl. J. Med. 1991, 324, 1685-1690. [CrossRef]

10. Ang, K.K.; Zhang, Q.; Rosenthal, D.I.; Nguyen-Tan, P.F.; Sherman, E.J.; Weber, R.S.; Galvin, J.M.; Bonner, J.A.; Harris, J.; El-Naggar, A.K.; et al. Randomized Phase III Trial of Concurrent Accelerated Radiation Plus Cisplatin with or Without Cetuximab for Stage III to IV Head and Neck Carcinoma: RTOG 0522. J. Clin. Oncol. 2014, 32, 2940-2950. [CrossRef]

11. Bonner, J.A.; Chin, S.; Spencer, S. Cetuximab and Radiotherapy in Laryngeal Preservanion-Reply. JAMA Otolaryngol. Neck Surg. 2017, 143, 526. [CrossRef] [PubMed]

12. Bonner, J.A.; Giralt, J.; Harari, P.; Spencer, S.; Schulten, J.; Hossain, A.; Chang, S.-C.; Chin, S.; Baselga, J. Cetuximab and Radiotherapy in Laryngeal Preservation for Cancers of the Larynx and Hypopharynx: A Secondary Analysis of a Randomized Clinical Trial. JAMA Otolaryngol. Neck Surg. 2016, 142, 842-849. [CrossRef] [PubMed]

13. Bonner, J.A.; Harari, P.M.; Giralt, J.; Cohen, R.B.; Jones, C.U.; Sur, R.K.; Raben, D.; Baselga, J.; Spencer, S.A.; Zhu, J.; et al. Radiotherapy plus cetuximab for locoregionally advanced head and neck cancer: 5-year 
survival data from a phase 3 randomised trial, and relation between cetuximab-induced rash and survival. Lancet Oncol. 2010, 11, 21-28. [CrossRef]

14. Bonner, J.A.; Harari, P.M.; Giralt, J.; Azarnia, N.; Shin, N.M.; Cohen, R.B.; Jones, C.U.; Sur, R.; Raben, D.; Jassem, J.; et al. Radiotherapy plus Cetuximab for Squamous-Cell Carcinoma of the Head and Neck. N. Engl. J. Med. 2006, 354, 567-578. [CrossRef]

15. De Raucourt, D.; Rame, J.-P.; Louis, M.-Y. [Principal treatments of head and neck cancer]. La Rev. Prat. 2006, $56,1662-1666$.

16. Blanchard, D.; Barry, B.; De Raucourt, D.; Choussy, O.; Dessard-Diana, B.; Hans, S.; Lafarge, D. Guidelines update: Post-treatment follow-up of adult head and neck squamous cell carcinoma: Screening for metastasis and metachronous esophageal and bronchial locations. Eur. Ann. Otorhinolaryngol. Head Neck Dis. 2015, 132, 217-221. [CrossRef] [PubMed]

17. Halimi, C.; Barry, B.; De Raucourt, D.; Choussy, O.; Dessard-Diana, B.; Hans, S.; Lafarge, D. Guidelines of the French Society of Otorhinolaryngology (SFORL), short version. Diagnosis of local recurrence and metachronous locations in head and neck oncology. Eur. Ann. Otorhinolaryngol. Head Neck Dis. 2015, 132, 287-290. [CrossRef]

18. Boysen, M.; Lövdal, O.; Winther, F.; Tausjö, J. The value of follow-up in patients treated for squamous cell carcinoma of the head and neck. Eur. J. Cancer 1992, 28, 426-430. [CrossRef]

19. Haas, I.; Hauser, U.; Ganzer, U. The dilemma of follow-up in head and neck cancer patients. Eur. Arch. Oto-Rhino-Laryngol. 2001, 258, 177-183. [CrossRef]

20. Snow, G.B. Follow-up in patients treated for head and neck cancer: How frequent, how thorough and for how long? Eur. J. Cancer 1992, 28, 315-316. [CrossRef]

21. O'Meara, W.P.; Thiringer, J.K.; Johnstone, P.A. Follow-up of head and neck cancer patients post-radiotherapy. Radiother. Oncol. 2003, 66, 323-326. [CrossRef]

22. Ritoe, S.C.; Krabbe, P.F.M.; Kaanders, J.H.A.M.; Hoogen, F.J.A.V.D.; Marres, H.A.M. Value of routine follow-up for patients cured of laryngeal carcinoma. Cancer 2004, 101, 1382-1389. [CrossRef] [PubMed]

23. Fornasa, F. Diffusion-weighted Magnetic Resonance Imaging: What Makes Water Run Fast or Slow? J. Clin. Imaging Sci. 2011, 1, 27. [CrossRef] [PubMed]

24. Sinkus, R.; Van Beers, B.E.; Vilgrain, V.; DeSouza, N.; Waterton, J. Apparent diffusion coefficient from magnetic resonance imaging as a biomarker in oncology drug development. Eur. J. Cancer 2012, 48, 425-431. [CrossRef] [PubMed]

25. Hamstra, D.A.; Rehemtulla, A.; Ross, B.D. Diffusion Magnetic Resonance Imaging: A Biomarker for Treatment Response in Oncology. J. Clin. Oncol. 2007, 25, 4104-4109. [CrossRef]

26. Harry, V.N.; Semple, S.I.; E Parkin, D.; Gilbert, F.J. Use of new imaging techniques to predict tumour response to therapy. Lancet Oncol. 2010, 11, 92-102. [CrossRef]

27. Padhani, A.R.; Liu, G.; Koh, D.-M.; Chenevert, T.L.; Thoeny, H.C.; Takahara, T.; Dzik-Jurasz, A.; Ross, B.D.; Van Cauteren, M.; Collins, D.; et al. Diffusion-Weighted Magnetic Resonance Imaging as a Cancer Biomarker: Consensus and Recommendations. Neoplasia 2009, 11, 102-125. [CrossRef]

28. Surov, A.; Ginat, D.T.; Sanverdi, E.; Lim, C.T.; Hakyemez, B.; Yogi, A.; Cabada, T.; Wienke, A. Use of Diffusion Weighted Imaging in Differentiating Between Maligant and Benign Meningiomas. A Multicenter Analysis. World Neurosurg. 2016, 88, 598-602.

29. Surov, A.; Meyer, H.-J.; Wienke, A. Can apparent diffusion coefficient (ADC) distinguish breast cancer from benign breast findings? A meta-analysis based on 13847 lesions. BMC Cancer 2019, 19, 955. [CrossRef]

30. Wang, J.; Takashima, S.; Takayama, F.; Kawakami, S.; Saito, A.; Matsushita, T.; Momose, M.; Ishiyama, T. Head and Neck Lesions: Characterization with Diffusion-weighted Echo-planar MR Imaging. Radiology 2001, 220, 621-630. [CrossRef]

31. Driessen, J.P.; Caldas-Magalhaes, J.; Janssen, L.M.; Pameijer, F.A.; Kooij, N.; Terhaard, C.H.J.; Grolman, W.; Philippens, M.E.P. Diffusion-weighted MR Imaging in Laryngeal and Hypopharyngeal Carcinoma: Association between Apparent Diffusion Coefficient and Histologic Findings. Radiology 2014, 272, 456-463. [CrossRef] [PubMed]

32. Meyer, H.-J.; Leifels, L.; Hamerla, G.; Höhn, A.K.; Surov, A. ADC-histogram analysis in head and neck squamous cell carcinoma. Associations with different histopathological features including expression of EGFR, VEGF, HIF-1 $\alpha$, Her 2 and p53. A preliminary study. Magn. Reson. Imaging 2018, 54, $214-217$. [CrossRef] [PubMed] 
33. Surov, A.; Meyer, H.J.; Wienke, A. Can Imaging Parameters Provide Information Regarding Histopathology in Head and Neck Squamous Cell Carcinoma? A Meta-Analysis. Transl. Oncol. 2018, 11, 498-503. [CrossRef] [PubMed]

34. Surov, A.; Clauser, P.; Chang, Y.-W.; Li, L.; Martincich, L.; Partridge, S.C.; Kim, J.Y.; Meyer, H.-J.; Wienke, A. Can diffusion-weighted imaging predict tumor grade and expression of Ki-67 in breast cancer? A multicenter analysis. Breast Cancer Res. 2018, 20, 58. [CrossRef] [PubMed]

35. Kyriazi, S.; Collins, D.; Messiou, C.; Pennert, K.; Davidson, R.; Giles, S.; Kaye, S.; DeSouza, N. Metastatic Ovarian and Primary Peritoneal Cancer: Assessing Chemotherapy Response with Diffusion-weighted MR Imaging_Value of Histogram Analysis of Apparent Diffusion Coefficients. Radiology 2011, 261, 182-192. [CrossRef]

36. Meyer, H.-J.; Fiedler, E.; Kornhuber, M.; Spielmann, R.P.; Surov, A. Comparison of diffusion-weighted imaging findings in brain metastases of different origin. Clin. Imaging 2015, 39, 965-969. [CrossRef]

37. Garbajs, M.; Strojan, P.; Surlan-Popovic, K. Prognostic role of diffusion weighted and dynamic contrast-enhanced MRI in loco-regionally advanced head and neck cancer treated with concomitant chemoradiotherapy. Radiol. Oncol. 2019, 53, 39-48. [CrossRef]

38. Kim, S.; Loevner, L.; Quon, H.; Sherman, E.; Weinstein, G.; Kilger, A.; Poptani, H. Diffusion-weighted magnetic resonance imaging for predicting and detecting early response to chemoradiation therapy of squamous cell carcinomas of the head and neck. Clin. Cancer Res. 2009, 15, 986-994. [CrossRef]

39. Galbán, C.J.; Mukherji, S.K.; Chenevert, T.L.; Meyer, C.R.; Hamstra, D.A.; Bland, P.H.; Johnson, T.D.; Moffat, B.A.; Rehemtulla, A.; Eisbruch, A.; et al. A Feasibility Study of Parametric Response Map Analysis of Diffusion-Weighted Magnetic Resonance Imaging Scans of Head and Neck Cancer Patients for Providing Early Detection of Therapeutic Efficacy. Transl. Oncol. 2009, 2, 184-190. [CrossRef]

40. Cui, Y.; Zhang, X.-P.; Sun, Y.-S.; Tang, L.; Shen, L. Apparent Diffusion Coefficient: Potential Imaging Biomarker for Prediction and Early Detection of Response to Chemotherapy in Hepatic Metastases. Radiology 2008, 248, 894-900. [CrossRef]

41. Surov, A.; Meyer, H.J.; Wienke, A. Associations between apparent diffusion coefficient (ADC) and KI 67 in different tumors: A meta-analysis. Part 1: ADCmean. Oncotarget 2017, 8, 75434-75444.

42. Surov, A.; Meyer, H.J.; Wienke, A. Associations between apparent diffusion coefficient (ADC) and KI 67 in different tumors: A meta-analysis. Part 2: ADCmin. Oncotarget 2018, 9, 8675-8680. [CrossRef] [PubMed]

43. Nunnally, J.C.; Bernstein, I.H.; Berge, J.M.t. Psychom Theory; McGraw-Hill: New York, NY, USA, 1967.

44. Vandecaveye, V.; De Keyzer, F.; Nuyts, S.; Deraedt, K.; Dirix, P.; Hamaekers, P.; Poorten, V.V.; Delaere, P.R.; Hermans, R. Detection of head and neck squamous cell carcinoma with diffusion weighted MRI after (chemo)radiotherapy: Correlation between radiologic and histopathologic findings. Int. J. Radiat. Oncol. 2007, 67, 960-971. [CrossRef] [PubMed]

45. Razek, A.A.K.A.; Kandeel, A.; Soliman, N.; El-Shenshawy, H.; Kamel, Y.; Nada, N.; Denewar, A. Role of Diffusion-Weighted Echo-Planar MR Imaging in Differentiation of Residual or Recurrent Head and Neck Tumors and Posttreatment Changes. Am. J. Neuroradiol. 2007, 28, 1146-1152. [CrossRef] [PubMed]

46. Vogel, D.W.T.; Zbaeren, P.; Geretschlaeger, A.; Vermathen, P.; De Keyzer, F.; Thoeny, H.C. Diffusion-weighted MR imaging including bi-exponential fitting for the detection of recurrent or residual tumour after (chemo)radiotherapy for laryngeal and hypopharyngeal cancers. Eur. Radiol. 2012, 23, 562-569. [CrossRef] [PubMed]

47. Vandecaveye, V.; Dirix, P.; De Keyzer, F.; De Beeck, K.O.; Poorten, V.V.; Hauben, E.I.; Lambrecht, M.; Nuyts, S.; Hermans, R. Diffusion-Weighted Magnetic Resonance Imaging Early After Chemoradiotherapy to Monitor Treatment Response in Head-and-Neck Squamous Cell Carcinoma. Int. J. Radiat. Oncol. 2012, 82, 1098-1107. [CrossRef] [PubMed]

48. King, A.; Chow, K.-K.; Yu, K.-H.; Mo, F.K.F.; Yeung, D.K.W.; Yuan, J.; Bhatia, K.S.; Vlantis, A.; Ahuja, A.T. Head and Neck Squamous Cell Carcinoma: Diagnostic Performance of Diffusion-weighted MR Imaging for the Prediction of Treatment Response. Radiology 2013, 266, 531-538. [CrossRef]

49. De Perrot, T.; Lenoir, V.; Ayllón, M.D.; Dulguerov, N.; Pusztaszeri, M.; Becker, M. Apparent Diffusion Coefficient Histograms of Human Papillomavirus-Positive and Human Papillomavirus-Negative Head and Neck Squamous Cell Carcinoma: Assessment of Tumor Heterogeneity and Comparison with Histopathology. Am. J. Neuroradiol. 2017, 38, 2153-2160. [CrossRef] 
50. Ryan, W.R.; Fee, W.E.; Le, Q.-T.; Pinto, H.A. Positron-Emission Tomography for Surveillance of Head and Neck Cancer. Laryngoscope 2005, 115, 645-650. [CrossRef]

51. Yao, M.; Luo, P.; Hoffman, H.T.; Chang, K.; Graham, M.M.; Menda, Y.; Tan, H.; Buatti, J.M. Pathology and FDG PET Correlation of Residual Lymph Nodes in Head and Neck Cancer After Radiation Treatment. Am. J. Clin. Oncol. 2007, 30, 264-270. [CrossRef]

52. Subramaniam, R.M.; Truong, M.; Peller, P.; Sakai, O.; Mercier, G. Fluorodeoxyglucose-Positron-Emission Tomography Imaging of Head and Neck Squamous Cell Cancer. Am. J. Neuroradiol. 2009, 31, 598-604. [CrossRef] [PubMed]

53. Kim, E.S.; Yoon, D.Y.; Moon, J.Y.; Baek, S.; Han, Y.M.; Seo, Y.L.; Yun, E.J. Detection of loco-regional recurrence in malignant head and neck tumors: A comparison of CT, MRI, and FDG PET-CT. Acta Radiol. 2018, 60, 186-195. [CrossRef] [PubMed]

54. Preda, L.; Conte, G.; Bonello, L.; Giannitto, C.; Travaini, L.L.; Raimondi, S.; Summers, P.; Mohssen, A.; Alterio, D.; Rocca, M.C.; et al. Combining standardized uptake value of FDG-PET and apparent diffusion coefficient of DW-MRI improves risk stratification in head and neck squamous cell carcinoma. Eur. Radiol. 2016, 26, 4432-4441. [CrossRef] [PubMed]

55. Yom, S.S.; Machtay, M.; Biel, M.A.; Sinard, R.J.; El-Naggar, A.K.; Weber, R.S.; Rosenthal, D.I. Survival Impact of Planned Restaging and Early Surgical Salvage Following Definitive Chemoradiation for Locally Advanced Squamous Cell Carcinomas of the Oropharynx and Hypopharynx. Am. J. Clin. Oncol. 2005, 28, 385-392. [CrossRef] [PubMed]

56. Kowalski, L.P.; Waltonen, J.D.; Ozer, E.; Hall, N.C.; Schuller, D.E.; Agrawal, A. Results of Salvage Treatment of the Neck in Patients with Oral Cancer. Arch. Otolaryngol. Head Neck Surg. 2002, 128, 58-62. [CrossRef] [PubMed]

57. Mendenhall, W.M.; Villaret, U.B.; Amdur, R.; Hinerman, R.W.; Mancuso, A.A. Planned neck dissection after definitive radiotherapy for squamous cell carcinoma of the head and neck. Head Neck 2002, 24, 1012-1018. [CrossRef]

58. Sivan, V.; Vozenin, M.-C.; Tricaud, Y.; Lefaix, J.-L.; Cosset, J.-M.; DuBray, B.; Martin, M.T. Altered proliferation and differentiation of human epidermis in cases of skin fibrosis after radiotherapy. Int. J. Radiat. Oncol. 2002, 53, 385-393. [CrossRef]

59. Temam, S.; Koka, V.; Mamelle, G.; Julieron, M.; Carmantrant, R.; Marandas, P.; Janot, F.; Bourhis, J.; Luboinski, B. Treatment of the N0 neck during salvage surgery after radiotherapy of head and neck squamous cell carcinoma. Head Neck 2005, 27, 653-658. [CrossRef] 